1 PERSPECTIVE

2

3 New approaches in component design for dye-sensitized solar cells

4

5 AUTHOR LIST

6

7 Nick Vlachopoulos* and Anders Hagfeldt*

8 Laboratory of Photonics and Interfaces, Institute of Chemical Science and Engineering, Swiss Federal

9 Institute of Technology in Lausanne (EPFL), LSPM-ISIC-EPFL, Chemin des Alambics, Station 6, CH-

101015 Lausanne, Switzerland

11

12

lacopo Benesperi and Marina Freitag

13

aDepartment of Chemistry, Ångström Laboratory, Uppsala University, P. O. Box 523, SE-75120

Uppsala, Sweden

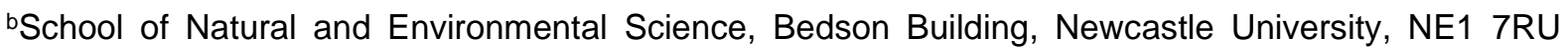
Newcastle upon Tyne, UK.

Ghufran Hashmi

a Microelectronics Research Unit, Faculty of Information Technology \& Electrical Engineering, P. O.

Box 8000, FI-90014, University of Oulu, Finland.

b Department of Applied Physics, Puumiehenkuja 2, 02150 Espoo, P. O. Box 15100, FI-00076

AALTO, Aalto University, Espoo-Finland.

Guobin Jia, Ruri Agung Wahyuono, Jonathan Plentz and Benjamin Dietzek 
ABSTRACT

29

30 The present perspective presents a number of issues related to the current direction of DSSC research, 31 with emphasis on the transition from iodide-containing electrolyte to charge-transport media (CTMs), electrolytes or solid-state conductors based on inorganic coordination complexes, aiming to attain a better light-to-electricity conversion efficiency, associated with larger photovoltage, and long-term stability. Such a change necessitates the concomitant introduction of novel dyes and counter electrodes. The first part of the perspective introduces an overview of the DSSC field and a number of considerations related to the transition from the triiodide/iodide-based CTM to CTMs based on alternative systems. Subsequently, the recent developments of CTM based on Cu coordination complexes are discussed, from the inorganic physical chemistry point of view, including some highlights about novel dyes associated to these CTMs. electrode substrates, related to the application of the aforementioned novel CTMs, are presented. 


\section{General overview}

Dye-sensitized solar cells (DSSC) can be foreseen as cost-efficient candidates for photovoltaic (PV) applications with multifarious manufacturing possibilities and short energy-payback times. Variable colour options with superior optical aesthetics, sustainable processability on a variety of substrates and high performance of this technology under diffuse light conditions could be used for building integrated photovoltaic cells and to power portable electronics. Our recent development of DSSCs based on organic dye sensitizers and Cu-complex redox systems has led to outstandingly high performance under ambient light, reaching a 32\% power conversion efficiency under 1000 lux fluorescent light source: this efficiency calculated with respect to the indoor light source not to the standard solar spectrum AM 1.5. (1) This corresponds to a power output of $101 \mu \mathrm{A} / \mathrm{cm}^{2}$ at $1000 \mathrm{Lux}$ and outperforms all other types of PV cells made of silicon, lead halide perovskites, organic PV cells and even gallium arsenide (GaAs) cells. Details on the DSSC development in the last 35 years are described in a number of reviews $(2,3,12-21,4,22,23,5-11)$ and in an edited book (24).

In a conventional DSSC, the photoelectrode consists of dye molecules anchored to a wide band gap semiconductor oxide, mostly titanium dioxide $\left(\mathrm{TiO}_{2}\right)$, forming a high surface area mesoporous photoelectrode (25). Either n-type or p-type oxide substrates can be used in DSSCs, with different types of dye in each case. However, the most efficient DSSCs, of interest to practical applications, are based on n-type oxide substrates. Therefore, only this type of DSSC will be discussed in the present review. Following light absorption, the dye molecules inject electrons to the conduction band of the oxide, and the oxidized dye molecules are regenerated by a species contained in the charge-transport medium (CTM) interposed between the dye-coated oxide layer and a dark counter electrode CE. The species effective in the regeneration reaction can be either a redox mediator in solution (e.g. iodide/tri-iodide, $\mathrm{I}_{3}{ }^{-} / \mathrm{I}^{-}$, a Cu $\mathrm{Cu}^{\prime \prime} / \mathrm{Cu}^{\prime}$ coordination complex) or a solid hole conductor $(\mathrm{HC})$. The cycle is completed at a counter electrode CE coated with a thin electrocatalytic layer of e.g. platinum, carbon, or electronically conducting polymer. The mesoporous oxide is usually deposited on a transparent conducting oxide (TCO) substrate, frequently F-doped tin oxide (FTO), with the incident light directed from the FTO side not covered by dye/oxide layer. In the case of some DSSCs of industrial interest, the oxide is deposited on a flexible metal substrate, e.g. stainless steel. In this case, the light is directed from the CE side of the DSSC, with the CE and CTM being sufficiently transparent so that the intensity of light reaching the oxide-supported dye layer is not substantially diminished. 
The direction for materials development of DSSC has drastically changed in the last years, with the main emphasis in replacing the $\mathrm{I}_{3}^{-} / \mathrm{I}^{-}$redox mediator by $\mathrm{Co}^{\mathrm{III/I}}$ and $\mathrm{Cu}^{11 / /}$ coordination complexes. The main motivation has been to reduce the driving force, the Gibbs free energy corresponding to the difference between the redox potential of the mediator and that of the ground state of the dye, for regenerating the oxidized dye by the reduced form of the redox couple.

The highest efficiency systems today for DSSCs are being achieved using organic dyes, mesoporous $\mathrm{TiO}_{2}$ and $\mathrm{Co}^{\mathrm{III/I}}$ or $\mathrm{Cu}^{\mathrm{II/I}}$ complex systems. The highest DSSC (not certified) solar-to-electric conversion efficiencies (PCE) exceeding 14\% have been achieved by Kakiage et al. (14.3\%, illuminated area $\left.\Sigma=0.10 \mathrm{~cm}^{2}\right)(26)$ and by Ji et al. $\left(14.1 \%\right.$, Co ${ }^{\prime \prime \prime \prime \prime I ~ m e d i a t o r) ~}(27)\left(14.1 \%, \Sigma=0.14 \mathrm{~cm}^{2}\right)$, both with a Co ${ }^{\prime \prime \prime \prime \prime \prime}$ mediator. The highest certified efficiency of $12.1 \%$ for DSSCs has been obtained in EPFL $\left(\Sigma=0.14 \mathrm{~cm}^{2}\right)$ with the $\mathrm{Cu}^{1 / / I}$ mediator, which is slightly higher than the previous certified record of $11.9 \%\left(\Sigma=1.0 \mathrm{~cm}^{2}\right)$ with the $\mathrm{I}_{3} / \mathrm{l}$ - mediator (28). The breakthroughs for the introduction of Co- and Cu-based system in DSSCs were initially announced by the group of Anders Hagfeldt, Gerrit Boschloo and Marina Freitag in Uppsala, Sweden and their collaborators, the groups of Lars Kloo and Licheng Sun in Stockholm, Sweden (29) (30). These approaches has been further developed at EPFL Switzerland (1,31-33). For Cu redox mediators in liquid electrolytes, the highest (not certified) PCE is $12.7 \%$ (34). In addition, a solid-state variant of the Cu-complex systems, generated by drying of the electrolyte, exhibited a PCEs of $11 \%$, $(35,36)$ which is the highest reported up-to-date for a solid-state DSSC.

$\mathrm{TiO}_{2}$ is by far the most popular wide band gap semiconductor and state-of-the art and it still is. The first studies of dye-sensitized porous $\mathrm{TiO}_{2}$ electrode were performed during the 1980 s by the Grätzel group in EPFL-Switzerland. These electrodes were prepared by the thermal decomposition of a solution of a Ti metalloorganic compound and needed the deposition of several thin oxide layers in order to achieve the desired thickness (37) (38). Soon thereafter an alternative type of porous $\mathrm{TiO}_{2}$, based on a mesoporous 5-10 $\mu \mathrm{m}$ thick layer made of colloidal nanoparticles with diameters of $15-40 \mathrm{~nm}$, was proposed in the seminal Nature paper by O'Regan and Grätzel (39). The size of the $\mathrm{TiO}_{2}$ particles and the film thickness have, however, to be optimized with respect to the specific dyes and CTMs used. The properties of the mesoporous colloidal electrode have been discussed by Barbé et al. ((25). In the earlier studies, the CTM was a liquid electrolyte containing a redox mediator, mostly triiodide-iodide $\left(\mathrm{I}_{3}^{-} \mathrm{I}^{-}\right)$. Larger particles give less surface area and larger pores. The former is a disadvantage for light harvesting and the film thickness need to be adjusted in relation to the light absorption properties of the dyes. For more viscous electrolytes, ionic liquids and solid-state systems larger pores may be needed to avoid mass transport limitations. For organic dyes and Cu/complex electrolytes typically $30 \mathrm{~nm}$ sized 
nanoparticles are used with a film thickness of 5-10 $\mu \mathrm{m}$. In this respect, it should be noted that the optimization of the $\mathrm{TiO}_{2}$ nanomaterials has been an important part of the international DSSC research.

For a substantial improvement of the DSSC efficiency, of particular importance has been the fact that the largest internal potential drop in DSSCs with organic dyes and $\mathrm{Cu}^{1 / 1 /}$-complex redox systems occurs in the electron injection process from the excited state of the dye to the conduction band of $\mathrm{TiO}_{2}$. The position of the conduction band, $\mathrm{E}_{\mathrm{C}}$, of $\mathrm{TiO}_{2}$ and also oxides in general can be tuned by varying the surface charge. For example, positive cations such as $\mathrm{H}^{+}$and $\mathrm{Li}^{+}$shifts $\mathrm{E}_{\mathrm{C}}$ to higher potentials (or lower energies), reducing the possible open circuit photovoltage, Uoc, and molecules with negative charge, such as the nitrogen lone pair on 4-tert butyl pyridine, shifts $E_{c}$ higher in energy possibly resulting to larger Uoc. This approach can be used for fine tuning, but for a more substantial increase of Uoc alternative oxides with higher energy $E_{C}$ need to be developed.

The upper limit of the DSSC open-circuit voltage for a given redox mediator $\operatorname{UOC}_{\mathrm{OLIM})}$ is determined by the difference between the conduction band edge $E_{c}$ and the redox Fermi level of the redox mediator $\mathrm{E}_{\mathrm{F}}(\mathrm{Ox} / \mathrm{Red})$, both measured with respect to a suitable reference electrode. In general, a shift of $E_{F}(O x / R e d)$ to a negative direction, corresponding to the shift of the equilibrium electrode potential $E$ (Ox/Red) to the positive direction, is expected to lead to an increase of $U_{\text {OC(LIM). }}$

Alternatively, from the semiconductor point of view, a strategy to develop semiconductors with higher $\mathrm{E}_{\mathrm{C}}$ will result to higher open-circuit voltages. From studies in single crystal materials, it is known that for several oxide semiconductors in aqueous solutions, notably zinc stannate $\left(\mathrm{Zn}_{2} \mathrm{SnO}_{4}\right)$, strontium and barium titanates $\left(\mathrm{SrTiO}_{3}, \mathrm{BaTiO}_{3}\right)$, and niobium oxide, $\left(\mathrm{Nb}_{2} \mathrm{O}_{5}\right)$, $\mathrm{E}_{\mathrm{C}}$ lies higher than for $\mathrm{TiO}_{2}$. If the same trend is followed for these oxides in nonaqueous solvents and for polycrystalline materials, then it would be advantageous to replace mesoporous $\mathrm{TiO}_{2}$ by one of the aforementioned alternative semiconductors in mesoporous form. However, other electrode substrate factors determining the DSSC, notably the roughness factor (real to geometric area) should not be detrimental to the DSSC performance.

Apart from liquid-based electrolytes, substantial advances have been achieved with solid-state DSSCs (sDSSCs) based on solid CTMs, also termed hole conductors (HCs). (21) (40) (41), in addition to the aforementioned one based on $\mathrm{Cu}^{\mathrm{Ill} / \mathrm{I}}$. In the case of organic, metal-free small-molecule HCs, the best attained efficiency has been $8 \%(42)$ in a DSSC based on an organic sensitizer and spiro-OMeTAD as HC. As regards conducting polymer-based HCs in DSSCs an effective approach in achieving effective penetration of the $\mathrm{HC}$ into the $\mathrm{TiO}_{2}$ pores is in-situ photoelectrochemical polymerization, initiated at the 
irradiated dye-coated electrode itself. With PEDOT as HC generated from bis-EDOT monomers, a completely solid DSSC showed a top PCE of $7 \%$. (43).

sDSSCs present some advantages as compared to DSSCs with liquid electrolytes. At first, the problems of evaporation and leaking of the electrolyte, requiring rigorous sealing, are avoided in sDSSCs. Another advantage is the lower changes in the solid CTM volume with temperature in SDSSCs as compared to these for liquid CTM. Finally, the photooxidized dye regeneration for several organic $\mathrm{HC}$ molecules is faster than for several redox mediators commonly used in liquid electrolyte-based DSSCs. On the other hand, the back reductive electron transfer reaction between oxidized $\mathrm{HC}$ and electrons in the mesoporous oxide or the TCO substrate is also faster for solid HCs. In over to overcome this drawback, the presence of a thin $\mathrm{TiO}_{2}$ blocking layer or underlayer interposed between the porous dye-supporting oxide and the transparent TCO oxide is necessary. An underlayer is also beneficial to the performance of a liquid CTM-based DSSC, both for reducing the dark current and improving the adhesion of the mesoporous oxide layer to the TCO substrate. However, the requirements for the blocking behaviour of an underlayer are more stringent in the case of SDSSCs.

A DSSC configuration intermediate to the liquid-electrolyte DSSC and the solid-state DSSC (sDSSC) is achieved by the immobilization of the electrolyte into a solid matrix. This phase can be either inorganic, e.g. based on aluminosilicates, or organic, e.g. polymeric. Such DSSCs are termed quasisolid DSSCs. However, in this case the drawbacks associated with the liquid electrolyte are not eliminated but just decreased.

Besides redox couples and hole conductors the key material components in DSSC are the dye and the semiconductor oxide. Some useful insights concerning the choice of DSSC dyes are presented in Section 3.

Organic sensitizers based on the donor-ா-acceptor (D-ா-A) motif have been widely explored in solar energy conversion applications. The high molar extinction coefficients, rare-metal-free structures, and most importantly the facile molecular tailoring resulting to tunable PV performances are the main reasons for the development of D-m-A sensitizers. (44,45,54,46-53). Compared to classic ruthenium sensitizers, pure organic sensitizers are very promising candidates with comparable high-power conversion efficiency (PCE) and long-term stability, especially for future commercial and practical applications. 
In general, most organic sensitizers are synthesized with the D-ח-A configuration, due to the efficient intramolecular charge transfer (ICT) properties. $(55,56)$ An additional group of electron-withdrawing conjugated components has been recently introduced into the $\pi$-bridge of the $D-\pi-A$ framework to function as an auxiliary electron acceptor. The additional acceptor in the $D-A-\pi-A$ motif not only contributes to modulate the energy levels, absorption spectra, and PV performances, but also significantly improves the photostability of sensitizers. (57-59)

$\mathrm{TiO}_{2}$ is still by far the most popular wide band gap, state-of-the art, semiconductor since the seminal Nature paper by O'Regan and Grätzel (39), in which the use of a colloidal mesoporous layer in DSSCs was proposed. However, a huge number of publications on different nanostructures such as nano-rods and tubes and alternative binary and ternary oxides have created a vast library that can be used to choose optimal morphological, optical and electrical properties for the demand at hand. A comprehensive overview of the various oxide semiconductors used in DSSC can be found in the review by Aumaitre et al (60). Some oxides with potentially higher conduction band energy than $\mathrm{TiO}_{2}$ are zinc stannate $\left(\mathrm{Zn}_{2} \mathrm{SnO}_{4}\right)$, strontium and barium titanates $\left(\mathrm{SrTiO}_{3}, \mathrm{BaTiO}_{3}\right)$ and niobium pentoxide $\left(\mathrm{Nb}_{2} \mathrm{O}_{5}\right)$. The motivation is that the quasi-Fermi level of the semiconductor under illumination can then be higher in energy (lower work function or more negative electrochemical potential) and thus lead to a higher open-circuit cell voltage $\left(U_{o c}\right)$.

As regards the dark, in the sense of not needing light for its operation, counter electrode, the first generation of dye-sensitized solar cells (DSSCs) was mainly produced by employing counter electrodes (CEs) based on platinum (Pt) as an electrocatalyst material, mostly deposited in microdispersed form on non-transparent TCO substrate. (61)(62) Platinum is the electrocatalyst of choice for a wide range of electrochemical energy conversion devices. Some of the advantages of $\mathrm{Pt}$ are their high catalytic activity, conductivity and high chemical stability against iodine species.

Furthermore, $\mathrm{Pt}$ it is less expensive than other noble metals with similar properties (e.g. Ir, Rh). Due to its high catalytic activity and chemical stability in the DSSCs, as well as its high transparency for DSSC applications requiring it, e.g. in the case of cells based on dye/ $/ \mathrm{TiO}_{2}$ deposited on a metal substrate, or in DSSC used as windows in BIPV applications, Pt/TCO remained for a long time as the foremost choice for designing high efficiency solar cells. (63-65) By combining iodide/triiodide redox shuttle-based electrolytes with an efficient Pt-based CEs, the DSSCs have exhibited an impressive (11\%) certified solar-to-electrical conversion efficiency. (66) 
212 However, platinum is a precious metal, and the Pt-based CEs may result in a high cost, especially if

213 large-area solar harvesting is desired. Moreover, alternative CEs with even lower transparency may be needed for some applications. Additionally, as a result of the advancements in materials research for DSSCs, the traditional Pt-based CEs were not found compatible for electrolytes containing novel redox shuttles (i.e. cobalt or copper-based) $(67,68)$. Therefore, efforts have been made to investigate and develop alternative CE catalytic counter electrodes, such as carbonaceous materials, discussed in following sections of this review, to achieve not only high solar-to-electrical conversion efficiency but also reproducible and long-term PV performance stability. (69) (70) (71) (72). The field of DSSC CEs has been recently reviewed in the two-volume book by Yun and Hagfeldt (73). In addition to carbons, several other CE materials have been tested. In addition to carbons, three additional categories of electrocatalyst materials are electronically conducting polymers, e.g. polypyrrole, polyaniline, and PEDOT, transition metal inorganic compounds, for example carbides, nitrides, oxides and sulfides, and organic thiolates. A frequently, easy to prepare conducting polymer CE is PEDOT electrodeposited on TCO from an aqueous colloidal EDOT solution with n-dodecyl sulfate (SDS) as supporting electrolyte, as proposed by Ellis et al. (74). Additionally, hybrid materials combining several of components in the aforementioned categories have been considered, e.g. Pt/carbon or conducting polymer/carbon.

\section{Novel copper redox mediators}

Advancements in consumer technologies, with new findings in the field of dye sensitized solar cells (DSSCs), have opened up market niches in which DSSCs can thrive by taking full advantage of their peculiarities. The advantages of DSSCs for indoor applications over other solar cell technologies are threefold. (75) First, different dyes can be developed to exactly match the illumination spectrum of the photon source present in the environment in which they should operate, harvesting their light with high efficiency. Since light bulbs emit in the visible range, the poor efficiency of organic and metalorganic light absorbers in the UV and IR regions over their inorganic counterparts is irrelevant here. Second, DSSCs can be completely made from non-toxic materials. Given the indoor environment, there is a higher chance that these solar cells might get in contact with people during operation. Therefore, in case of failures or breaks, it is important that any leaked or exposed chemical is not harmful to humans. Third, the setbacks of DSSCs, which limit their use at full sun illumination, such as stability and efficiency in full sun conditions, do not play a prominent role in low light conditions. Indeed, DSSCs are currently the highest-performing solar cell technology in a low illumination setup, with efficiencies up to $34 \%$ and generated power up to $100 \mu \mathrm{W} \mathrm{cm}-2$ at 1000 lux for a relatively large $3.2 \mathrm{~cm}^{2}$ device, outclassing all of their competitors. (76) 
247 In the world of IT and electronics Artificial Intelligence, Machine Learning, and the Internet of Things 248 are setting a shift in paradigm for how data is acquired and processed; the concepts of smart homes 249 and smart buildings are entering general public daily conversations and news. Networks of sensors 250 coupled with processing units capable of autonomous decisions promise to optimize the use of heating, 251 cooling and lighting in buildings, thus reducing energy consumption. However, there is a concern that the power required to run this optimization network might nullify the energy savings that said network provides. Recently, Freitag and coworkers have demonstrated that DSSCs, when coupled with a supercapacitor as an energy buffer, are capable of powering a completely autonomous sensing and processing network, without the need of batteries or mains power.(76) By taking advantage of light that is already present inside a building, DSSCs ensure that the optimization performed by the intelligent network fully translates to energy savings.

Redox mediators based on copper complexes, some of which are shown in Fig. 1, play a crucial role in the outstanding performance of DSSCs in ambient lighting. This class of materials is capable of efficiently regenerating a dye with just $100 \mathrm{mV}$ of driving force, (77) thus maximizing the voltage output of the solar cell. Moreover, they can retain this high voltage (close to $1 \mathrm{~V}$ ) even in low lighting conditions, which is very important to properly power electronic devices with a small number of solar cells connected in series. In addition to yielding a high photovoltage, copper complexes show a reduced recombination rate and a higher diffusion length compared to other popular redox mediators, such as cobalt complexes, providing higher photocurrents and better fill factors in similar systems. (78) Regarding the long-term operational stability of DSSCs, copper complexes have a clear advantage over the most used redox mediator - iodine/iodide - as they are not corrosive. However, liquid DSSCs are not regarded as stable devices in general, due to electrolyte solution leakages over time related to the difficulty of perfectly sealing the device. Furthermore, the presence of liquid in the device is unwelcomed regardless of leakages, because an accidental device breakage would lead to a spillage of chemicals in liquid form. For commercial applications, solid-state DSSCs are considered the most viable option.

273 Solid-state DSSCs have historically lagged behind their liquid counterparts, but this is no longer true 274 thanks to copper complex redox mediators and their ability to give life to "zombie" devices. $(35,79)$ In 275 short, a "zombie" device is a liquid DSSC in which the electrolyte solvent is completely evaporated, leaving behind a dried-out electrolyte solution. Such a device should be non-functional (dead). However, if the redox mediator is comprised of a copper complex (or, with lesser results, a cobalt complex (80)), the device still works very efficiently (a living dead). The most efficient solid-state DSSC fabricated to date features a "zombified" copper complex hole transporting material $\left(\mathrm{Cu}(\mathrm{tmby})_{2}\right)$ and is even higher 
performing than its liquid counterpart. (36) Copper complexes have reduced energy losses during their

281 transition from a reduced to an oxidized state compared to iodine/iodide (which undergoes a

282 complicated two-electron oxidation process) and cobalt complexes (which transition from high spin to

283 low spin upon oxidation), (43) but are not completely free from them. In particular, $\mathrm{Cu}(\mathrm{I})$ employs a

284 tetrahedral geometrical configuration, while $\mathrm{Cu}$ (II) ideal geometry is tetragonal or square planar. The

285 most widely used copper complexes in DSSC are comprised of two bidentate ligands, which try to

286 suppress this geometrical transformation by employing bulky moieties in key positions, which hinder

287 the rotation of the two ligands upon oxidation/reduction. A better approach to further reduce this energy

288 loss is to use tetradentate ligands, which have a much more rigid structure and block both complex's

289 oxidation states in the same geometry. Recently, Michaels et al. have demonstrated that the use of a

290 tetradentate ligand ( $\mathrm{Cu}(\mathrm{oxabpy}))$ indeed reduces voltage losses compared to a bidentate one. (81) The

291 finding of a copper complex with a tetradentate ligand and an ideal redox potential could lead to a new

292 efficiency record for both liquid and solid-state DSSCs in the future. Zerk et al. have conducted

293 experimental work on a tridentate copper complex with a hydroxide counter-ion in the fourth

294 coordination position $(\mathrm{LCuOH})$ to evaluate its reorganization energy. The rate constant for electron self-

295 exchange determined using the Marcus cross relation was $k_{11}=3 \times 10^{4} \mathrm{M}^{-1} \mathrm{~s}^{-1}$ at $-88^{\circ} \mathrm{C}$, leading to 296 an estimated value of $9 \times 10^{6} \mathrm{M}^{-1} \mathrm{~S}^{-1}$ at $25^{\circ} \mathrm{C}$, which is one of the highest values known for copper297 based redox couples. With further Marcus analysis, they also determined a low reorganization energy, $298 \lambda=0.95 \pm 0.17 \mathrm{eV}$, attributed to minimal structural variation between the redox partners. (82) In an 299 interesting study Imahori and coworkers showed copper complexes with several 1,10-phenanthroline300 based ligands with substitutions in the 2,9 positions $\left(\mathrm{Cu}(\mathrm{dmp})_{2}, \mathrm{Cu}(\mathrm{bp})_{2}, \mathrm{Cu}(\mathrm{emp})_{2}, \mathrm{Cu}(\mathrm{dep})_{2}\right.$ and

$\left.301 \mathrm{Cu}(\mathrm{dpp})_{2}\right)$, for which they attained moderate to high power conversion efficiencies $(6-11 \%)$ with a high

302 Uoc over $1.0 \mathrm{~V}$. The difference in performance was rationalized by different electron collection 303 efficiencies. (83) 


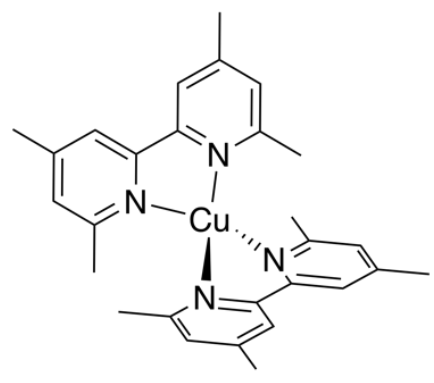

$\mathrm{Cu}(\text { tmby })_{2}$<smiles></smiles>

$\mathrm{Co}(\mathrm{bpy})_{3}$

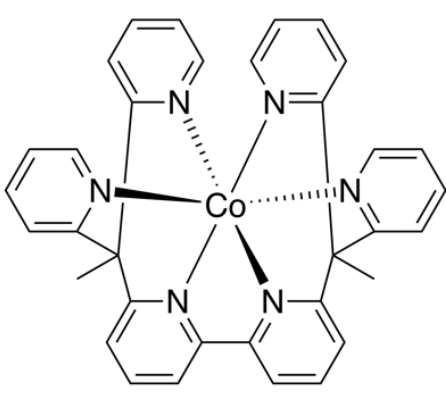

Co(bpyPY4)

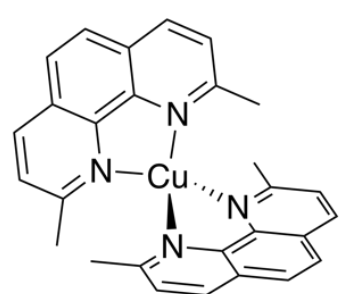

$\mathrm{Cu}(\mathrm{dmp})_{2}$

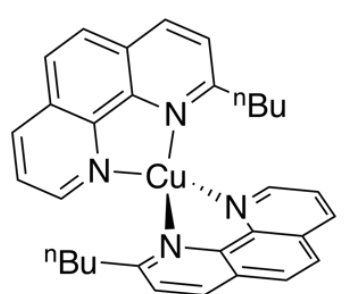

$\mathrm{Cu}(\mathrm{bp}) 2$

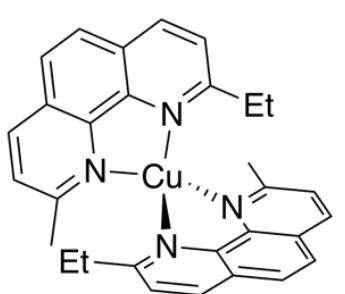

$\mathrm{Cu}(\mathrm{emp})_{2}$

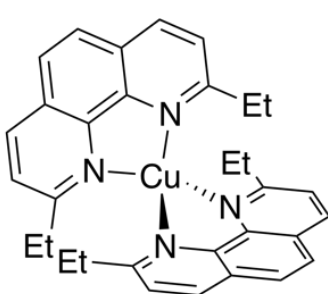

$\mathrm{Cu}(\mathrm{dep})_{2}$

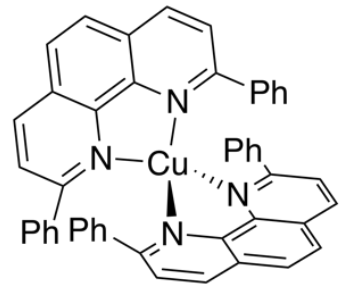

$\mathrm{Cu}(\mathrm{dpp})_{2}$

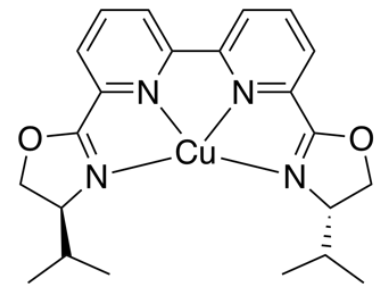

Cu(oxabpy)

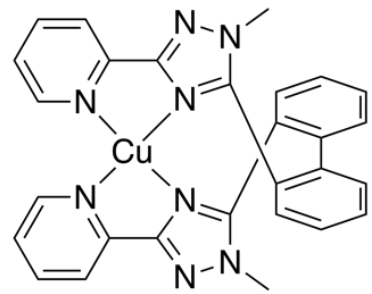

$\mathrm{Cu}(2)$<smiles></smiles>

$\mathrm{LCuOH}$

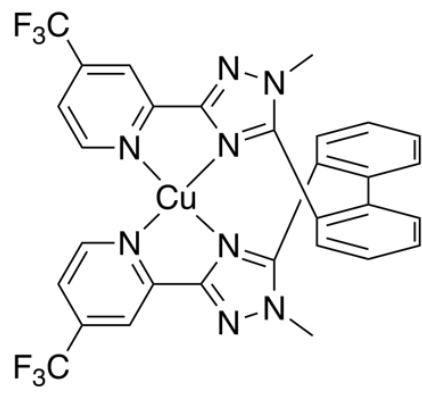

$\mathrm{Cu}(3)$

Fig. 1. Structures of metal complex electrolytes/hole transporting materials used for the fabrication of liquid/solid state DSSCs discussed in this perspective.

Three copper-based redox shuttles $[\mathrm{Cu}(1), \mathrm{Cu}(2)$, and $\mathrm{Cu}(3)]$ featuring tetradentate neutral polyaromatic ligands were synthesized and evaluated computationally, electrochemically, and in DSSC devices using a benchmark organic dye - Y123 - by Roberta Rodrigues et al. They calculated that the inner-sphere electron transfer reorganization energies $(\lambda=0.34-0.53 \mathrm{eV})$ for copper complexes were 
314 significantly lower than that evaluated for the $\mathrm{Co}(\mathrm{bpy})_{3}(\lambda=0.61 \mathrm{eV})$ redox shuttle. Their rigid tetradentate

315 ligand design promotes more efficient electron transfer reactions leading to an improved Jsc (14.1 mA $\mathrm{cm}^{-2}$ ), higher stability due to the chelate effect, and a decrease the loss in Uoc for one of the copper redox shuttle-based devices.(84) A different strategy to increase the performance of copper-based solar cells and to decrease recombination processes was used by Glinka et al. The PV performance of solar cells sensitized with the D205 indoline dye and its new derivative comprising an alkoxysilyl anchoring unit (D205Si) was enhanced in the presence of Cucurbit[7]uril (see Fig. 2) as molecular multi-capper, thanks to a reduced electron recombination between titania and electrolyte. Indoline dyes were also found to be regenerated outstandingly fast by the Cu-based mediator (time constant shorter than 100 ns).(85) Composition and cell parameters of DSSCs fabricated with the discussed metal complex electrolytes are listed in Table 1.

Table 1. Electrolyte/dye composition and photovoltaic parameters of DSSCs based on referenced metal complexes.

\begin{tabular}{|c|c|c|c|c|c|c|}
\hline Electrolyte & Dye & $U_{o c}(\mathrm{~V})$ & $\begin{array}{c}\mathrm{JSC}_{\mathrm{Sc}}(\mathrm{mA} \\
\left.\mathrm{cm}^{-2}\right)\end{array}$ & FF (\%) & PCE (\%) & Reference \\
\hline Co(bpyPY4) & Y123 & 0.768 & 12.1 & 62 & 5.68 & 44 \\
\hline $\mathrm{Cu}\left(\mathrm{tmby}_{2}\right)_{2}$ & WS-72 & 1.07 & 13.8 & 79 & 11.7 & 9 \\
\hline Cu(oxabpy) & Y123 & 0.92 & 9.75 & 69 & 6.2 & 45 \\
\hline $\mathrm{Cu}(\mathrm{bp})_{2}$ & LEG4 & 0.842 & 10.6 & 66.4 & 5.90 & 47 \\
\hline $\mathrm{Cu}(\mathrm{dmp})_{2}$ & LEG4 & 1.03 & 10.0 & 60.9 & 6.29 & 47 \\
\hline $\mathrm{Cu}(\mathrm{emp})_{2}$ & LEG4 & 0.823 & 7.52 & 52.6 & 3.25 & 47 \\
\hline $\mathrm{Cu}(\mathrm{dep})_{2}$ & LEG4 & 0.813 & 6.77 & 46.4 & 2.56 & 47 \\
\hline $\mathrm{Cu}(\mathrm{dpp})_{2}$ & LEG4 & 0.848 & 4.18 & 62.4 & 2.21 & 47 \\
\hline $\mathrm{Cu}(1)$ & Y123 & 689 & 5.7 & 77 & 3.1 & 48 \\
\hline $\mathrm{Cu}(2)$ & Y123 & 693 & 10.2 & 72 & 4.7 & 48 \\
\hline $\mathrm{Cu}(3)$ & Y123 & 792 & 7.9 & 75 & 4.3 & 48 \\
\hline $\mathrm{Co}(\mathrm{bpy})_{3}$ & Y123 & 818 & 14.6 & 73 & 8.9 & 48 \\
\hline $\mathrm{Cu}(\mathrm{tmby})_{2}$ & D205 & 0.92 & 6.12 & 82 & 4.60 & 49 \\
\hline $\mathrm{Cu}(\text { tmby })_{2}$ & D205Si & 0.95 & 6.40 & 78 & 4.75 & 49 \\
\hline
\end{tabular}

328 
333 Apart from indoor PV cells, the other potential key application for DSSCs is that of BIPV cells. For a 334 long time, it was believed that nice-looking, colored, electricity-generating windows based on DSSCs 335 would enter the market and generate high revenues. However, while small, artistic windows could 336 definitely have a niche market, from a bulk energy production point of view colored windows do not 337 make sense. In a scenario where DSSCs replace plain glass in large windows, or even full-glass 338 buildings, these cells have to be (almost) colorless, because nobody wants to live behind a colored filter 339 for several hours per day. Fortunately, the emission spectrum of our Sun is very broad, and visible light 340 is only a part (albeit a consistent one) of it. The fabrication of a DSSC absorbing light only in the UV 341 (ultra-violet) and IR (infra-red) regions, especially one the size of a window, would still generate a 342 significant amount of electricity. In recent years, research efforts have focused on the synthesis of 343 efficient near-IR (NIR) and IR dyes exactly for this purpose. Completely colorless dyes have not been 344 discovered yet, but this goal is getting closer and closer. 


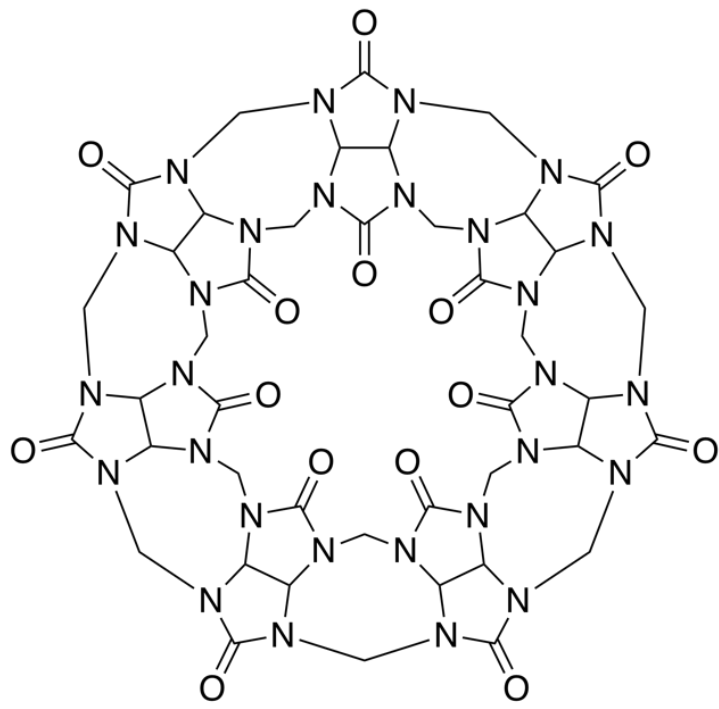

Cucurbit[7]uril<smiles>[C+]N1C(=O)C(=c2sc(=Cc3ccc4c(c3)C3CCCC3N4C(C=C)=CC)c(=O)n2CC(=O)O)SC1=S</smiles>

D205

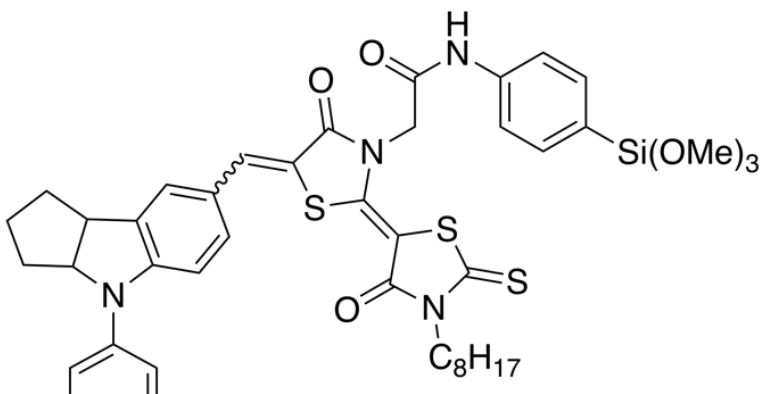

D205Si<smiles></smiles><smiles></smiles>

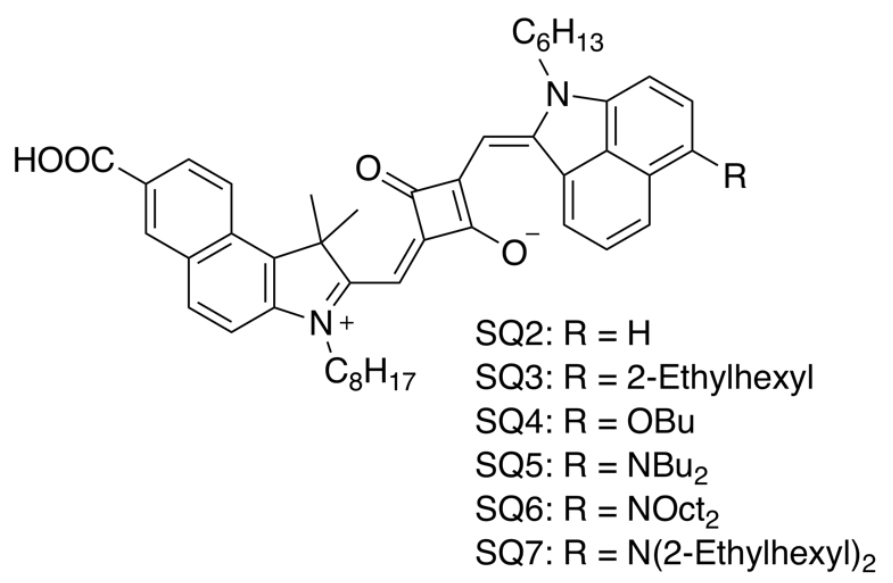

Fig. 2. Structures of dyes used with copper complex electrolytes and of NIR dyes discussed in this perspective.

Extending dye absorption to the NIR region translates to reducing the energy gap between the dye's HOMO and LUMO. In a DSSC, the energy level of significance that is almost always fixed is that of 
352 titania's conduction band. With that in mind, reducing the dye bandgap involves stabilizing the dye's

353 excited state - to lower the LUMO to an energy level just high enough to properly inject electrons into

354 the mesoporous $\mathrm{TiO}_{2}$ layer - and, more importantly, destabilizing the dye's ground state - to raise the

355 HOMO energy level and reduce the gap to the LUMO. Not many functional groups have low energy

356 transitions that allow absorption in the NIR region; the most studied ones to date are boron-

357 dipyrromethenes (BODIPY) and squaraines. Dyes based on each of the functional groups have

358 absorption peaks with very high molar extinction coefficients in the order of $10^{5} \mathrm{M}^{-1} \mathrm{~cm}^{-1}$ in the far-

$359 \mathrm{red} / \mathrm{NIR}$ region of the spectrum, with peak maxima between 650 and $800 \mathrm{~nm}$. They usually also feature

360 a secondary, less intense absorption peak in the violet/blue region up to $450 \mathrm{~nm}$, with a significant lack

361 of absorption between 450 and $600 \mathrm{~nm}$. The most NIR-shifted dye reported to date for the BODIPY

362 class of materials has been prepared by Kubota et al. and features a peak maximum close to $800 \mathrm{~nm}$

363 both in solution and on titania (dye 6).(86) A DSSC fabricated with such dye has an efficiency of $1.1 \%$,

364 which is only slightly lower than that of a similar but less red-shifted dye (1.4\%, dye 5). For what

365 concerns squaraines, Haishima et al. report on seven different dyes with NIR absorption (SQ1-SQ7).

366 (87) The most red-shifted dye has a peak maximum of $820 \mathrm{~nm}$ in solution (SQ6, cell efficiency of $0.25 \%$ ),

367 while the best performing dye leads to a cell efficiency of $1.3 \%$ (SQ3, its peak maximum is $796 \mathrm{~nm}$ in

368 solution). The structures of the aforementioned dyes are depicted in Fig. 2, while cell parameters of

369 DSSCs fabricated with them are listed in Table 2, together with their maximum absorption wavelength.

370 The quest to colorless DSSCs is not limited to the finding of suitable, efficient dyes. Such devices will

371 also need colorless redox mediators and/or hole transporting materials with suitable energy levels for

372 NIR dye regeneration. (88)

373

374 Table 2. Dye/electrolyte composition (with dye's maximum absorption wavelength) and photovoltaic

375 parameters of DSSCs based on referenced NIR dyes.

\begin{tabular}{lccccccc}
\hline Dye & $\lambda_{\max }(\mathrm{nm})$ & Electrolyte & Uoc $(\mathrm{V})$ & $J_{\mathrm{Sc}}\left(\mathrm{mA} \mathrm{cm}^{-2}\right)$ & $\mathrm{FF}(\%)$ & $\mathrm{PCE}(\%)$ & Reference \\
\hline Dye 5 & 783 & lodine & 0.431 & 4.98 & 65 & 1.40 & 50 \\
Dye 6 & 812 & lodine & 0.435 & 3.96 & 65 & 1.12 & 50 \\
SQ1 & 771 & lodine & 0.300 & 4.39 & 56 & 0.74 & 51 \\
SQ2 & 784 & lodine & 0.300 & 6.22 & 47 & 0.89 & 51 \\
SQ3 & 796 & lodine & 0.315 & 9.20 & 45 & 1.31 & 51 \\
SQ4 & 806 & lodine & 0.266 & 3.81 & 56 & 0.56 & 51 \\
SQ5 & 818 & lodine & 0.276 & 1.77 & 59 & 0.29 & 51 \\
SQ6 & 820 & lodine & 0.289 & 1.45 & 60 & 0.25 & 51 \\
SQ7 & 815 & lodine & 0.279 & 2.05 & 52 & 0.30 & 51 \\
\hline
\end{tabular}


3764 Carbonaceous materials-based catalyst layers as alternative 377 counter electrodes for novel electrolytes.

378

379

380

381

382

383

384

385

386

387

388

389

390

391

392

393

394

395

396

397

398

399

400

401

402

403

404

405

406

407

408
Carbon based nanomaterials such as carbon nanotubes (CNTs) and graphene are based on an earthabundant element, and the availability is unlimited. The price drops significantly below that of the platinum for large scale production. Moreover, these carbon-based nanomaterials have high chemical inertness against corrosive chemicals and surroundings, and are very well suited to be used for the counter electrodes (CEs) in DSSCs. Recent investigations with graphene, single- and multi-walled CNTs (MWCNTs) based CEs have demonstrated comparable catalytic activity, chemical stability, and conversion efficiency, and they potentially have much better conductivity than these based on Pt/TCO. $(67,89-92)$ Therefore, they will be the most promising candidates for a sustainable development of the DSSCs replacing the Pt for large scale production.

\subsection{Counter electrodes for cobalt electrolytes}

A thick and porous carbon-based CE as potential alternative catalyst material for DSSCs was first reported by A. Kay and co-workers for efficient triiodide reduction. (93) As a result of realizing the salient features i.e. low cost, high surface area, and promising catalytic activity, this pioneer work has been remained a great motivation for the researchers worldwide to develop other novel carbonaceous catalysts layers, which have also been frequently tested with the novel redox shuttles in the DSSCs. $(68,69)$

From the electrolyte progress perspective, iodine electrolytes have been surpassed by cobalt electrolytes due to the flexibility in the alteration of their redox potential, which provides an opportunity to achieve a higher open circuit voltage in the DSSCs. Therefore, efforts have also been made to develop novel carbonaceous catalysts for testing with these novel cobalt electrolytes. (93)

In this regard, Kavan et al reported graphene nanoplatelets (GNP) as alternative CE material for DSSC, which revealed striking (9.4\%) solar-to-electrical conversion efficiency along with notable (878 $\mathrm{mV})$ open circuit voltage $\left(U_{O C}\right)$ as a result of observing smaller charge transfer resistance $\left(R_{C T}\right)$ compared to traditional Pt CEs. (93) 
409 Similarly, Stefik et al developed carbon-graphene nano-composite catalyst materials and investigated

410 the photovoltaic performances of the fabricated DSSCs employing cobalt electrolytes. They also 411 achieved similar conversion efficiencies (> $9 \%$ ) by varying the amount of graphene in their developed 412 carbon-graphene composites. They reported low $R_{\text {CT }}\left(1 \Omega \mathrm{cm}^{2}\right)$ with a $20 \%$ weight content of graphene 413 adjusted in formulating the composite, which caused an improved fill factor in the fabricated DSSC compared to Pt CEs (CE) - based DSSCs. (94)

415

Moreover, Liu et al demonstrated a comparison to prove the superior catalytic activity of carbon black in nanoparticle form as low-cost CE electrocatalytic material for cobalt based electrolytes in DSSCs.

418 (69) The electrochemical behavior of both the carbon black catalyst and traditional Pt/TCO CEs was analyzed by performing cyclic voltammetry (CV) and electrochemical impedance spectroscopy measurements, which suggested lower $\left(0.39 \Omega \mathrm{cm}^{2}\right) R_{\mathrm{CT}}$ values for carbon black CEs than these of $\mathrm{Pt}$ nanoparticle-based CEs $\left(1.19 \Omega \mathrm{cm}^{2}\right)$. Consequently, the DSSCs fabricated with these catalytic carbon black CEs employing Co mediators and Y123 dye exhibited an impressive (8.81\%) solar-to-electrical conversion efficiency, indicating the potential of carbon black as one of the potential CEs for these novel electrolytes. (69)

Currently, the highest solar-to-electrical conversion efficiency (14.3\%, not certified) reported for a DSSC employed a carbonaceous catalyst (i.e. graphene nanoplatelets) based $C E$, in conjunction with a cobalt electrolyte and the combination of co-adsorbed ADEKA-1 (alkoxysilyl-anchor dye) and LEG4 (carboxyanchor organic dye). (26) These preliminary reports about carbonaceous materials not only suggest that carbon-based catalyst materials could not only be categorized as the leading CEs but also point to the potential of overcoming the mass transport limitation for these bulky cobalt electrolytes by providing a large CE surface are, with a positive effect to the overall photovoltaic performance $(26,69)$.

Nevertheless, none of the above-mentioned studies reported long-term stability tests of the fabricated devices, which raises the concern about the chemical stability of these carbonaceous materials during the long-term photovoltaic performance of the fabricated DSSCs. Moreover, most of the electrolytes fabricated to produce these high efficiency devices were prepared with acetonitrile as solvent, $(26,95,96)$ which has not been recognized as a reliable organic solvent due to its possible leakage from the cell channels under stressful conditions. (97-99) Therefore, a combination of high boiling point solvent-based cobalt electrolytes (i.e. Y-butyrolactone or sulfolane) with these catalytic carbonaceous 


\subsection{Counter electrodes for copper electrolytes}

The pioneer research work reported by Freitag, Hagfeldt, Boschloo and co-workers regarding novel copper $(\mathrm{Cu})$ redox mediators suggested new opportunities for both liquid and solid state DSSCs. (29) As a result of providing numerous possibilities such as achieving high ( $>1 \mathrm{~V})$ open circuit voltage (Uoc) and rapid regeneration of adsorbed dye on semiconducting oxide layers (such as $\mathrm{TiO}_{2}$ ), (31) as well as contributing for an impressive power generation under low light intensities. $(1,75)$ These novel Cu redox shuttles give great motivation to develop the next class of DSSCs which could be used to generate electricity under both outdoors and indoor light intensity conditions.

The initial attempt in testing $\mathrm{Cu}$ redox based electrolytes in the DSSCs utilized Pt as the traditional catalyst material, which yielded $1.4 \%$ solar-to-electrical energy conversion efficiency. (102) Interestingly, a composite of Pt/Carbon black was incorporated by Bai et al. in DSSCs based on copper electrolytes, which exhibited an impressive $(7 \%)$ solar to electrical power conversion efficiency ( the authors reported lower electron transfer rates for several noble metals, conducting oxides, and carbon black alone as CE substrates, which consequently resulted low fill factors compared to the Pt/carbon black composite catalyst. (103)

Since these aforementioned reports, the electropolymerized PEDOT catalyst layer has been established as the alternative and standard catalyst material in producing high ПPCE DSSCs employing Cu electrolytes. $(1,31,75)$ In this regard, Freitag et al. and Saygili et al. reported DSSCs with very high $(>8-10 \%) \eta_{P C E}$, which also exhibited an impressive $(>1 \mathrm{~V})$ open circuit voltage $\left(U_{O C}\right)$ under full sun light intensities. $(31,77)$ Cao et al., have to-date reported the highest $(13 \%)$ ПPCE for a copper mediatorbased liquid electrolyte with a slight modification in the traditional DSSC embodiment, i.e. direct contacting of charge extracting layers, which surprisingly does not exhibit short circuiting when assembled with the type of electropolymerized PEDOT catalyst layers (1) discussed earlier.

\footnotetext{
On the other hand, a surprising serendipitous discovery was the transformation of copper-based liquid electrolyte into a solid-state hole conductor by evaporation of the solvent acetonitrile during storage, with the DSSC remaining functional in DSSC Wv. This conversion of a traditional DSSC into a solid DSSC opens several interesting opportunities for similar solid state DSSCs embodiments based on solid-state coordination complexes. A DSSC based on a solidified Cu hole conductor exhibited more than $11 \%$ ПPCE with promising preliminary stability. (35) These preliminary results offer great motivation to develop the technology further by performing intensely further long-term photovoltaic
} 
477 and chemical stability tests of DSSCs with copper redox systems and various novel CE materials

478 under established standardized stressful conditions. $(104,105)$

479

480

481

482

483

484

485

486

487

488

489

490

491

492

493

494

495

496

497

498

499

500

501

502

503

504

505

506

507

508

509

510

In this respect, for progressing with carbonaceous catalysts-based CEs, Kavan et al. investigated the electrochemical behavior of graphene-based CEs in DSSCs with Cu mediator-based liquid electrolytes and demonstrated comparable catalytic activity to that of these based on the electropolymerized PEDOT catalyst and superior to the Pt catalyst (92) Moreover, the same co-workers reported a highly catalytic composite catalyst, which was developed by integrating $\mathrm{Pt}$, platinum oxide (PtOx), graphene oxide, and graphene nanoplatelets, and was tested as CE in DSSCs with Cu electrolytes. (106) The fabricated composite outperformed the stand-alone catalyst materials (i.e. Pt, PEDOT and pure graphene) by showing high catalytic performance which led to very high $(9.5 \%-11.3 \%)$ ПPCE compared to stand-alone catalyst layers when measured in various light intensities. (106)

Very recently, Hashmi et al demonstrated printed single-walled carbon nanotubes (SWCNTs) as another potential alternative carbonaceous material, which was investigated as CE substrate and was compared with the Pt counter electrode- based DSSCs employing Cu electrolytes. (68) The printed SWCNTs outperformed Pt/TCO with superior catalytic activity i.e. exhibiting very low charge transfer resistance $\left(R_{\mathrm{CT}}=2-2.9 \Omega \mathrm{cm}^{2}\right)$ when tested with Cu electrolytes in both the complete DSSCs and in symmetrical CE-CE configurations. As a result, the fabricated DSSCs exhibited an impressive $7 \% \pm$ $0.4 \%$ ПPCE with a cell achieving $7.5 \%$ and $8.3 \%$ conversion efficiencies under full and half sun illumination respectively. (68)

Hence, all these results not only provide preliminary evidence regarding the potential of carbonaceous materials for producing high performance DSSCs with $\mathrm{Cu}$ electrolytes but also suggest the need to develop and investigate both stand alone as well as composite carbon-based catalysts, which could also provide high chemical stability along with long term stability that has not yet been established with these novel redox shuttles.

\subsection{Novel research directions with alternative redox shuttles and carbonaceous materials}

By observing the progress being made with both the cobalt and copper redox based electrolyte systems, futuristic research and further developments employing carbonaceous materials as CEs materials can be forecasted. 
512 For instance, the new device designs of DSSCs such as DSSC produced with direct contacting of 513 charge extracting layers or solid-state DSSCs employing Cu redox shuttles as hole conductors offer 514 new opportunities, with printed SWCNT as one of the novel carbonaceous materials which could be 515 used as an alternative catalyst and could contribute for performance improvement by providing high 516 conductivity and high porosity together with high specific surface area to achieve better catalytic performance along with better diffusion for the recently investigated bulky redox shuttles. $(107,108)$

519 On the other hand, the carbon black/graphite composite catalysts of the type used with the traditional iodine electrolytes $(93,109,110)$ also provide opportunities to produce more affordable and cost-efficient CEs, which can also be printed via established scalable methods such as screen printing or inkjet printing. Although electropolymerized PEDOT catalyst layers has been standardized and demonstrated with cobalt and copper redox electrolytes, the scalability of such layers has not yet been established by any research group. Contrary to this, fabrication of the printable carbonaceous pastes has not only been demonstrated in several reports but also been available commercially from a number of material providers. Hence, the integration of these cost-efficient carbon black/graphite composites is expected to be integrated in the novel device designs of DSSCs discussed above.

Moreover, similar to the Pt/Graphene composites reported by Kavan et al., (106) the development of more blends of carbonaceous materials and PEDOT may also be forecasted, of the type which has already been reported for both rigid and flexible DSSCs employing iodine electrolytes. $(111,112)$ More interestingly, dry transferable SWCNT films (113), which have been successfully demonstrated in DSSCs and Perovskite solar cells $(114,115)$ can also be opted for as electrocatalysts CEs of these advanced and futuristic DSSCs, with the additional advantage of contributing to the lowering of the CE resistance.

537 Nevertheless, keeping the current trend in mind with efforts mostly dedicated to improve the solar-to538 electrical conversion efficiencies with advanced materials, it may also be forecasted that the futuristic 539 research work for these next generation DSSCs will focus more towards developing more robust 540 devices, for which the long-term device stability corresponding to every combination of materials could 541 be reported, with certified stability tests performed by independent sources. In this regard, several interesting long-term stability studies under standardized stress conditions could be predicted, such as observing the degradation of novel Cu redox mediator-based advanced electrolytes in the DSSCs with both glass photoelectrode (PE) and CE substrates, or, additionally, their corrosive behavior when either 
545 the PE or the CE are metal supported. This way, the best combination of electrolyte and counter 546 electrode materials contributing to robust stability could be established.

548 4. Recently developed processes in preparing carbonaceous 549 counter electrodes

550

551

In general, the processing of carbon based nanomaterials is difficult, and previous researches with graphene and CNTs based counter electrodes have used spin and dip coating, (116) inkjet printing, (117) or drop casting $(118,119)$ of graphene containing suspension or composites, these processes are able to prepare conductive graphene thin layer. However, these processes can be hardly controlled to prepare well-ordered graphene thin films, since usually a large amount of such carbon nanomaterials have to be used to achieve the desired catalytic activity. Consequently, the counter electrodes have poor optical transparency or even completely opaque, resulting to the loss of one of the striking features of the DSSCs, i.e. the aesthetic aspect for building integrated photovoltaic cell (BIPV) applications.

Emerging technologies such as the double self-assembly (DSA) process (120-123) enables the manipulation of low-cost graphene flakes and CNTs to form a well-ordered uniform large-area monolayer at the water/air interface, since it attempts to minimize the system energy. These flakes form a strict monolayer floating on the water surface; however, they are seldom connected to each other due to electrostatic repulsion between the flakes, and a lateral electrical conductivity is not expected if this loose monolayer is deposited on the substrate. In order to force the graphene flakes to connect to each other for achieving the necessary electrical conductivity, the conventional Langmuir-Blodgett (LB) process uses two mechanical barriers moving against each other to compress the floating monolayer of graphene flakes (MGFs), and the deposition of the densified MGFs can be done by dip coating of substrate. However, for the conventional LB process this approach works only on flat hydrophilic surfaces.

572 The DSA process works without using the mechanical barriers. Instead, surfactant molecules are used 573 to compress the graphene flakes to form a dense monolayer, and the densified multilayer graphene 574 flakes (MGFs) can be easily deposited onto substrates placed beneath it either by pumping out of the 575 water or by dip coating. $(121,122)$ Especially, the DSA process does not require the substrate surface 576 to be hydrophilic, and the resulted dense MGFs can be deposited almost on any substrates, including 577 rigid, flexible, and even on 3D surfaces, attributed to the synergetic interaction of the MGFs and the SDS surfactant molecules. Moreover, the DSA process can be used to deposit other nanomaterials 
579 such as CNTs, (123) and it can be repeated to deposit layer stacks or sandwich with well-controlled 580 morphology. (123)

582 As shown in Fig. 3, SEM image shows such MGFs connected with each other at the edge for the 583 electrical conductivity, and the optical transmission of the MGFs can be as high as $\sim 90 \%$ over a broad 584 wavelength range. The adhesion of the thin film is quite satisfied due to the strong van der Waals force on the flat surface. (122)

586

Recently the catalytic activity of various graphene or/and MWCNTs layer or bilayer consisting of a MGFs and a monolayer of MWCNTs in a $\mathrm{I}_{3}^{-} / \mathrm{I}^{-}$redox shuttle has been successfully tested, (123) which shows enhanced catalytic activities and chemical stability compared with Pt based counter electrode (CE) in ZnO-based DSSCs, resulting in open circuit voltage up to $702 \mathrm{mV}$, current density of $13.7 \mathrm{~mA} / \mathrm{cm}^{2}$, and conversion efficiency of $4.1 \%$, and the conversion efficiency exceeded that of the reference cells with Pt based CE. (123) Despite the non-ideal system with the ZnO-based DSSCs still under developing, the key information from this work is that the carbon-based nanomaterials are able to replace the precious Pt metal for the CE application, and perform even better than Pt-based CEs. It is therefore of great interest how such high-performance carbon nanomaterials based transparent conductive CEs behave in optimized systems, where already efficiencies higher than $10 \%$ have been demonstrated.

Nevertheless, we believe that the demonstrated properties of the carbon nanomaterials-based transparent conductive CEs meet the requirements for the high performance DSSCs in many aspects, and it is expected that such CEs may contribute greatly to the high performance DSSCs in the following cases:

603

604 1. Low-cost, earth-abundant and environmental-friendly carbon nanomaterials replacing Pt for a 605 sustainable development of DSSCs, and lower the cost of the DSSCs.

607 2. Highly transparent conductive electrodes, already applied in bifacial silicon solar cells (124), could 608 be applied for bifacial DSSCs. The concept of bifacial DSSC is explained by Wu et al. (125) These 609 cells have a much great potential for increasing power output per unit area (equivalent to effective efficiency). A $20-50 \%$ (with different back side contribution) increase of the equivalent effective efficiency has been demonstrated in silicon based thin film solar cells. (124) That means, for a 
612

613

614

615

616

617

618

619

620

621

622

623

624

625

626

627

628

629

630

631

632

633

634 $12-15 \%$. a

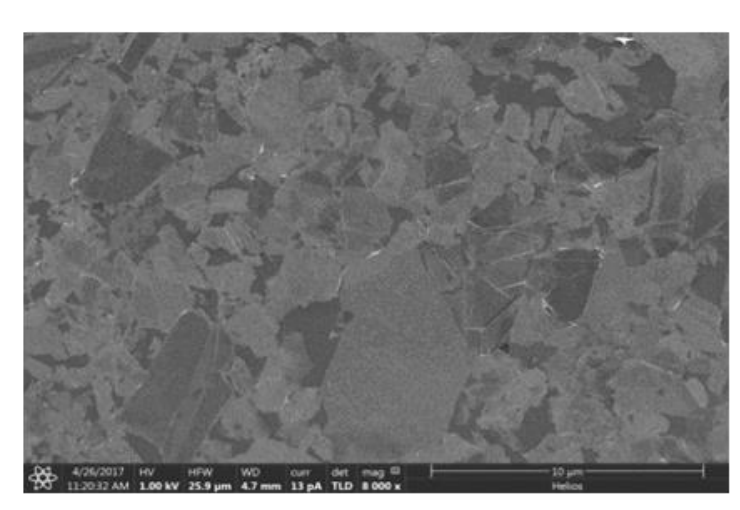

a the glass substrate).

monofacial DSSC with conversion efficiency of $10 \%$, an equivalent effective efficiency will be at around

3. The broadband transmission allow tandem DSSCs, and co-sensitized dyes working at different wavelengths for highly efficient DSSCs, in order to better harvest the energy from the solar spectrum.

4. Low temperature processing allow the DSSCs be fabricated on low-cost, flexible substrates such as plastics, textiles, this will reduce not only the material cost of the DSSCs, but also the thermal budget for the calcination of the Pt precursor. Furthermore, this feature allows the development of wearable and flexible DSSCs as the alternative avenue of smart e-textile research. (126)

5. Potentially the carbon nanomaterials-based counter electrodes could reach an ultralow sheet resistance by proper engineering such as thermal annealing, doping, surface functionalization, and chemical reduction (127)(128) of the thin film, which is critical for large-area DSSCs.

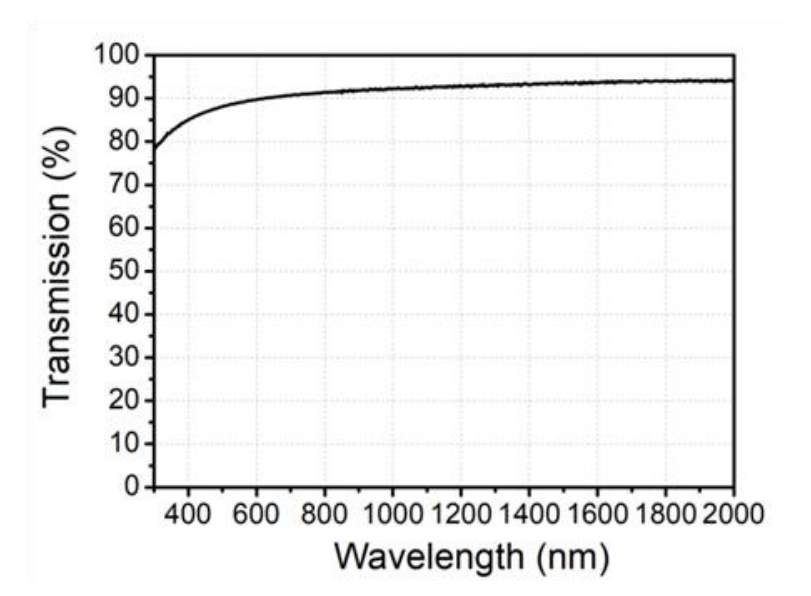

b

Fig. 3: a. SEM image showing multilayer graphene flakes with them connected to each other at their edges; $b$. The transmission spectrum of the MGFs (corrected spectrum neglecting the contribution of 
635

636

637

638

639

640

641

642

643

644

645

646

647

648

649

650

651

652

653

654

655

656

657

658

659

660

661

662

663

664

665

666

667

668

In summary, we have demonstrated the perspective of using carbon-based nanomaterials for the CEs in DSSCs. Especially, we have focused on the reproducible development of the carbon nanomaterialbased high transparency and conductivity CEs prepared by DSA process. It is noted that the performance of the commercial graphene and CNT source materials varies greatly with different production methods; As a result, there will be a lot of work to do to select the proper materials. Furthermore, there is considerable room left for the pre- and post-deposition treatments of the source materials to improve the performance of the final DSSC devices.

\section{Conclusions}

Until around 2010, the most efficient DSSC configurations were based on Ru coordination complex sensitizers with the triiodide/iodide redox system in a non-aqueous electrolyte and a Pt-coated counter electrode. More recently, the situation drastically changer with the introduction of other redox mediators, mainly coordination complexes of cobalt and ruthenium, in conjunction with the replacement of the $R u$ dye with metal-free organic dyes. This change has been necessitated due to the fact that the deleterious recombination reaction between oxide electrons and oxidized mediator, more pronounced for the oneelectron, kinetically simple, new mediators than for the two-electron, kinetically complex, triiodide/iodide system, is lower. Furthermore, the platinum-based counter electrodes were less performant that alternative counter electrodes, including carbon-based counter electrodes, including recently developed varieties, like graphene and carbon nanotubes. Carbonaceous counter electrodes, based on an inexpensive Earth-abundant element, would be obviously preferable to these based on noble metals for large-scale applications. In this respect, several novel forms of carbonaceous materials introduced to several fields of technology should be also of benefit to dye-sensitized solar cells. Novel materials in DSSCs offer the possibility to adapt them under variable illumination, outdoor or indoor illumination, to a wide range of applications, several of which, at the speculation stage at present, are expected to emerge in the foreseeable future.

\section{Acknowledgement}

Ghufran Hashmi is grateful to Jane and Aatos Erkkos Foundation for the CAPRINT project funding (\#243035481) and Dean's funding for highly ranked applicant at Department of Applied Physics at Aalto University (Decision \# 164/2018). Guobin Jia, Ruri Agung Wahyuono, Jonathan Plentz and Benjamin Dietzek gratefully acknowledge the provision of funding for parts of this work by the German Free State of Thuringia (TAB), co-financed by the European Social Fund (ESF) and European Regional 
669 Development Fund (ERDF) within the projects "ESTI" (2019 FGR 0080) and "FEST" (2016 FE 9028). 670 They are also thankful to Dr. Martin Lohe from Sixonia Tech GmbH for providing the graphene flakes 671 suspension, to Dr. Andrea Dellith (IPHT) for the SEM image, and to Ms. Barbara Geisenhainer (IPHT) 672 for the optical measurements.

673

674 
677 1) Cao $Y$, Liu $Y$, Zakeeruddin SM, Hagfeldt A, Grätzel M. Direct Contact of Selective Charge 678 Extraction Layers Enables High-Efficiency Molecular Photovoltaics. Joule. 2018; 2: 1108-1117.

2) Ardo S, Meyer GJ. Photodriven heterogeneous charge transfer with transition-metal compounds anchored to $\mathrm{TiO}_{2}$ semiconductor surfaces. Chem Soc Rev. 2009; 38: 115-164.

682

3) Benesperi I, Michaels H, Freitag M. The researcher's guide to solid-state dye-sensitized solar cells. J Mater Chem C. 2018; 6: 11903-11942.

685

686

4) Bisquert J, Cahen D, Hodes G, R??hle S, Zaban A, Rühle S, et al. Physical Chemical Principles of Photovoltaic Conversion with Nanoparticulate, Mesoporous Dye-Sensitized Solar Cells. J Phys Chem B. 2004; 108: 8106-8118.

689

690 5) Figgemeier E, Hagfeldt A. Are dye-sensitized nano-structured solar cells stable? An overview of 691 device testing and component analyses. Int J Photoenergy. 2004; 6: 127-140.

692

693 6) Freitag M, Boschloo G. The revival of dye-sensitized solar cells. Curr Opin Electrochem. 2017; 694 2: 111-119.

695

696 7) Grätzel M. Photoelectrochemical cells. Vol. 414, Nature. Nature Publishing Group; 2001; 1: 338697344.

698

699 8) Grätzel M. Solar energy conversion by dye-sensitized photovoltaic cells. Inorg Chem. 2005; 44 : $700 \quad 6841-6851$.

702 9) Grätzel M. Recent Advances ins sensitized Mesoscopic Solar Cells. Acc Chem Res. 2009; 42: $703 \quad 1788-1798$.

705 10) Hagfeldt A, Grätzel M. Light-Induced Redox Reactions in Nanocrystalline Systems. Chem Rev. 706 1995; 95: 49-68.

11) Hagfeldt A, Grätzel M. Molecular photovoltaics. Acc Chem Res. 2000; 33: 269-277. 
710 12) Hagfeldt A, Boschloo G, Sun L, Kloo L, Pettersson H. Dye-sensitized solar cells. Chem Rev. 711 2010; 110: 6595-6663.

712

13) Halme J, Vahermaa P, Miettunen K, Lund P. Device physics of dye solar cells. Adv Mater. 2010; 22: E210-E234.

715

716

14) McEvoy AJ, Grätzel M. Sensitisation in photochemistry and photovoltaics. Sol Energy Mater Sol Cells. 1994; 32: 221-227.

718

719

15) Meyer GJ. The 2010 millennium technology grand prize: dye-sensitized solar cells. ACS Nano. 2010; 4: 4337-4343.

721

722

16) Mohiuddin O, Obaidullah M, Sabah C. Improvement in dye sensitized solar cells from past to present. Opt. Quantum Electron. 2018; 50: 377.

17) O'Regan BC, Durrant JR, O'Regan BC, Durrant JR, O'Regan BC, Durrant JR. Kinetic and energetic paradigms for dye-sensitized solar cells: moving from the ideal to the real. Acc Chem Res. 2009; 42: 1799-1808.

728

18) Peter L. Characterization and Modeling of Dye-Sensitized Solar Cells. ECS Trans. 2007; 6: 555-

19) Peter LMLM. Dye-sensitized nanocrystalline solar cells. Phys Chem Chem Phys. 2007; 9: 26302642.

20) Rondán-Gómez V, Montoya De Los Santos I, Seuret-Jiménez D, Ayala-Mató F, Zamudio-Lara A, Robles-Bonilla T, et al. Recent advances in dye-sensitized solar cells [Internet]. Vol. 125, Appl. Phys. A. $2019 ; 125: 836$.

21) Vlachopoulosa N, Zhang J, Hagfeldta A. Dye-sensitized solar cells: New approaches with organic solid-state hole conductors. Chimia. 2015; 69: 41-51. 
742

743

744

745

746

747

748

749

750

751

752

753

754

755

756

757

758

759

760

761

762

763

764

765

766

767

768

769

770

771

772

773

774

775

776

22) Vlachopoulos N, Hagfeldt A. Photoelectrochemical cells based on dye sensitization for electricity and fuel production. Chimia. 2019; 73: 894-905.

23) Watson DF, Meyer GJ. Electron injection at dye-sensitized semiconductor electrodes. Annu Rev Phys Chem. 2005; 56: 119-156.

24) Kalyanasundaram K. Dye-sensitized solar cells. Lausanne: EPFL Press; 1990.

25) Barbe CJ, Arendse F, Comte P, Jirousek M, Lenzmann F, Shklover V, et al. Nanocrystalline titanium oxide electrodes for photovoltaic applications. J Am Ceram Soc. 1997; 80: 3157-71.

26) Kakiage K, Aoyama Y, Yano T, Oya K, Fujisawa J-IJ, Hanaya M. Highly-efficient dye-sensitized solar cells with collaborative sensitization by silyl-anchor and carboxy-anchor dyes. Chem Commun. 2015; 51: 15894-15897.

27) Ji J, Zhou H, Eom YK, Kim CH, Kim HK. 14.2\% Efficiency Dye-Sensitized Solar Cells by Cosensitizing Novel Thieno[3,2- b ]indole-Based Organic Dyes with a Promising Porphyrin Sensitizer. Adv Energy Mater. 2020; 10: 2000124.

28) Green MA, Dunlop ED, Hohl-Ebinger J, Yoshita M, Kopidakis N, Hao X. Solar cell efficiency tables (version 56). Prog Photovoltaics Res Appl. 2020; 28: 629-638.

29) Freitag M, Daniel Q, Pazoki M, Sveinbjörnsson K, Zhang J, Sun L, et al. High-efficiency dyesensitized solar cells with molecular copper phenanthroline as solid hole conductor. Energy Environ Sci. 2015; 5: 2634-2637.

30) Cong J, Kinschel D, Daniel Q, Safdari M, Gabrielsson E, Chen H, et al. Bis(1,1-bis(2pyridyl)ethane)copper(i/ll) as an efficient redox couple for liquid dye-sensitized solar cells. J Mater Chem A. 2016; 4: 14550-14554.

31) Saygili $Y$, Söderberg M, Pellet N, Giordano F, Cao Y, Munoz-García AB, et al. Copper Bipyridyl Redox Mediators for Dye-Sensitized Solar Cells with High Photovoltage. J Am Chem Soc. 2016; 138:15087-15096. 
32) Liu $Y$, Cao $Y$, Zhang W, Stojanovic M, Dar MI, Péchy $P$, et al. Electron-Affinity-Triggered Variations on the Optical and Electrical Properties of Dye Molecules Enabling Highly Efficient DyeSensitized Solar Cells. Angew Chemie - Int Ed. 2018; 57: 14125-14128.

33) Saygili $Y$, Stojanovic $M$, Michaels $H$, Tiepelt J, Teuscher J, Massaro A, et al. Effect of Coordination Sphere Geometry of Copper Redox Mediators on Regeneration and Recombination Behavior in Dye-Sensitized Solar Cell Applications. ACS Appl Energy Mater. 2018; 1: 4950-4962.

34) Ren Y, Flores-Díaz N, Zhang D, Cao Y, Decoppet JD, Fish GC, et al. Blue Photosensitizer with Copper(II/I) Redox Mediator for Efficient and Stable Dye-Sensitized Solar Cells. Adv Funct Mater. 2020; 2004804.

35) Cao Y, Saygili Y, Ummadisingu A, Teuscher J, Luo J, Pellet N, et al. 11\% Efficiency Solid-State Dye-Sensitized Solar Cells with Copper(II/I) Hole Transport Materials. Nat Commun. 2017; 8: 15390.

36) Zhang W, Wu Y, Bahng HW, Cao Y, Yi C, Saygili Y, et al. Comprehensive control of voltage loss enables 11.7\% efficient solid-state dye-sensitized solar cells. Energy Environ Sci. 2018; 11: 17791787.

37) Desilvestro J, Grätzel M, Kavan L, Moser J, Augustynski J. Highly Efficient Sensitization of Titanium Dioxide. J Am Chem Soc. 1985; 107: 2988-2990.

38) Vlachopoulos N, Liska P, Augustynski J, Grätzel M. Very Efficient Visible Light Energy Harvesting and Conversion by Spectral Sensitization of High Surface Area Polycrystalline Titanium Dioxide Films. J Am Chem Soc. 1988; 110:1216-1220.

39) O'Regan B, Grätzel M. A low-cost, high-efficiency solar cell based on dye-sensitized colloidal $\mathrm{TiO}_{2}$ films. Nature. 1991; 353: 737-740.

40) Zhang J, Freitag M, Hagfeldt A, Boschloo G. Solid-State Dye-Sensitized Solar Cells. In Tian H, BoschlooG, Hagfeldt A. (eds.) Molecular Devices for Solar Energy Conversion and Storage. Singapore: Springer-Nature; 2018. p.151-185. 
810 41) Snaith HJ. Solid-state dye sensitized solar cells incorporating molecular hole-transporters. In

811 Kalyanasundaram K. (ed.) Dye-Sensitized Solar Cells. Lausanne, Switzerland: EPFL Press; 2010. p. 812 163-206.

813

42) Xu B, Gabrielsson E, Safdari M, Cheng M, Hua Y, Tian H, et al. 1,1,2,2-Tetrachloroethane (TeCA) as a solvent additive for organic hole transport materials and its application in highly efficient solid-state dye-sensitized solar cells. Adv Energy Mater. 2015; 5: 1402340.

817

43) Zhang J, Vlachopoulos $\mathrm{N}$, Jouini M, Johansson MBMB, Zhang $\mathrm{X}$, Nazeeruddin MKMKMKMKMK, et al. Efficient solid-state dye sensitized solar cells: The influence of dye molecular structures for the insitu photoelectrochemically polymerized PEDOT as hole transporting material. Nano Energy. 2016; 19: 455-470.

822

823

44) Feldt SM, Gibson EA, Gabrielsson E, Sun L, Boschloo G, Hagfeldt A. Design of Organic Dyes and Cobalt Polypyridine Redox Mediators for High-Efficiency Dye-Sensitized Solar Cells. J Am Chem Soc. 2010; 132: 16714-16724.

826

45) Li LL, Diau EWG. Porphyrin-sensitized solar cells. Chem Soc Rev. 2013; 42: 291-304.

46) Liang M, Chen J. Arylamine organic dyes for dye-sensitized solar cells. Chem Soc Rev. 2013; 42: 3453-3488.

47) Hagberg DP, Edvinsson T, Marinado T, Boschloo G, Hagfeldt A, Sun L. A novel organic

48) Rühle S, Greenshtein M, Chen SG, Merson A, Pizem H, Sukenik CS, et al. Molecular adjustment of the electronic properties of nanoporous electrodes in dye-sensitized solar cells. J Phys Chem B. 2005; 109: 18907-18913.

838

49) Mao J, He N, Ning Z, Zhang Q, Guo F, Chen L, et al. Stable Dyes Containing Double Acceptors 51: 9873-9876. 
50) Liu B, Wang B, Wang R, Gao L, Huo S, Liu Q, et al. Influence of conjugated m-linker in D-D-m-A indoline dyes: Towards long-term stable and efficient dye-sensitized solar cells with high photovoltage. J Mater Chem A. 2014; 2: 804-812.

51) Mizuno $Y$, Yisilamu $Y$, Yamaguchi T, Tomura M. ( Dibenzoylmethanato ) boron Difluoride Derivatives Containing Triphenylamine Moieties : A New Type of Electron-Donor / p - Acceptor System for Dye-Sensitized Solar Cells. Chem. Eur. J. 2014; 20: 13286-13295.

52) Liu DS, Ding WL, Zhu KL, Geng ZY, Wang DM, Zhao XL. The master factors influencing the efficiency of D-A-т-A configurated organic sensitizers in dye-sensitized solar cell via theoretically characterization: Design and verification. Dyes Pigments. 2014, 105:192-201.

53) Grisorio R, De Marco L, Agosta R, lacobellis R, Giannuzzi R, Manca M, et al. Enhancing DyeSensitized Solar Cell Performances by Molecular Engineering: Highly Efficient $\pi$-Extended Organic Sensitizers. ChemSusChem. 2014; 7: 2659-2669.

54) Wang Y, Chen B, Wu W, Li X, Zhu W, Tian H, et al. Efficient Solar Cells Sensitized by Porphyrins with an Extended Conjugation Framework and a Carbazole Donor: From Molecular Design to Cosensitization. Angew Chemie Int Ed 2014; 53 :10779-10883.

55) Hong Y, Liao JY, Cao D, Zang X, Kuang D Bin, Wang L, et al. Organic dye bearing asymmetric double donor-ா-Acceptor chains for dye-sensitized solar cells. J Org Chem. 2011;76: 8015-8021.

56) Haid S, Marszalek M, Mishra A, Wielopolski M, Teuscher J, Moser J-EJ-E, et al. Significant Improvement of Dye-Sensitized Solar Cell Performance by Small Structural Modification in $\pi-$ Conjugated Donor-Acceptor Dyes. Adv Funct Mater [Internet]. 2012; 22: 1291-1302.

57) Holcombe TW, Yum J-H, Kim Y, Rakstys K, Grätzel M. Diketopyrrolopyrrole-based sensitizers for dye-sensitized solar cell applications: Anchor engineering. J Mater Chem A. 2013; 1: 13983-13978 .

58) Yum J-HJ-H, Holcombe TWTW, Kim Y, Yoon J, Rakstys K, Nazeeruddin MKMK, et al. Towards high-performance DPP-based sensitizers for DSC applications. Chem Commun. 2012; 48: 1072710729. 
877 59) Pei K, Wu Y, Wu W, Zhang Q, Chen B, Tian H, et al. Constructing Organic D-A-T-A-Featured 878 Sensitizers with a Quinoxaline Unit for High-Efficiency Solar Cells: The Effect of an Auxiliary Acceptor 879 on the Absorption and the Energy Level Alignment. Chem - A Eur J. 2012; 18: 8190-8200.

880

881 60) Aumaitre C, Joly D, Aldakov D, Demadrille R. Alternative Binary and Ternary Metal Oxides for Dye- and Quantum Dot-Sensitized Solar Cells. In: Lira-Cantú M. (ed.) The Future of Semiconductor Oxides in Next-Generation Solar Cells. Elsevier; 2018. p. 85-115.

884

61) Papageorgiou N. Counter-electrode function in nanocrystalline photoelectrochemical cell configurations. Coord Chem Rev. 2004; 248: 1421-1446.

887

62) Özkan M, Hashmi SG, Halme J, Karakoç A, Sarikka T, Paltakari J, et al. Inkjet-printed platinum counter electrodes for dye-sensitized solar cells. Org Electron. 2017; 44: 159-167.

890

891

63) Hashmi SG, Özkan M, Halme J, Misic KD, Zakeeruddin SM, Paltakari J, et al. High performance dye-sensitized solar cells with inkjet printed ionic liquid electrolyte. Nano Energy. 2015; 17: 206-215.

893

64) Hashmi G, Miettunen K, Peltola T, Halme J, Asghar I, Aitola K, et al. Review of materials and 895 manufacturing options for large area flexible dye solar cells. Renewable Sustainable Energy Rev. 2011; 15: $3717-3732$.

897

65) Yella A, Lee HW, Tsao HN, Yi C, Chandiran AK, Nazeeruddin MK, et al. Porphyrin-sensitized solar cells with cobalt (II/III)-based redox electrolyte exceed 12 percent efficiency. Science. 2011; 334: $629-634$.

901

902

66) Chiba Y, Islam A, Komiya R, Koide N, Han L. Conversion efficiency of $10.8 \%$ by a dye-sensitized solar cell using a $\mathrm{TiO}_{2}$ electrode with high haze. Appl Phys Lett. 2006; 88: 223505.

67) Yun S, Hagfeldt A, Ma T. Pt-Free Counter Electrode for Dye-Sensitized Solar Cells with High Efficiency. Adv Mater. 2014; 36: 6210-6237.

907

68) Hashmi SG, Sonai GG, Iftikhar H, Lund PD, Nogueira AF. Printed single-walled carbonnanotubes-based counter electrodes for dye-sensitized solar cells with copper-based redox mediators. 
912 69) Liu IP, Hou YC, Li CW, Lee YL. Highly electrocatalytic counter electrodes based on carbon black 913 for cobalt(iii)/(ii)-mediated dye-sensitized solar cells. J Mater Chem A. 2017; 5: 240-249.

915 70) Wu M, Sun M, Zhou H, Ma JY, Ma T. Carbon Counter Electrodes in Dye-Sensitized and 916 Perovskite Solar Cells. Adv Funct Mater. 2020; 30: 1906451.

71) Li G, Gao X. Low-Cost Counter-Electrode Materials for Dye-Sensitized and Perovskite Solar Cells. Adv Mater. 2020; 32: 1806478.

920

72) lqbal MZ, Khan S. Progress in the performance of dye sensitized solar cells by incorporating cost effective counter electrodes. Sol. Energy. 2018; 160: 130-152.

923

924

73) Yun S, Hagfeldt A. (eds.). Counter Electrodes for Dye-sensitized and Perovskite Solar Cells. Vols. 1-2. Weinheim, Germany: Wiley-VCH; 2018.

926

74) Ellis $\mathrm{H}$, Vlachopoulos $\mathrm{N}$, Häggman L, Perruchot $\mathrm{C}$, Jouini M, Boschloo G, et al. PEDOT counter electrodes for dye-sensitized solar cells prepared by aqueous micellar electrodeposition. Electrochim Acta. 2013;107:45-51.

75) Freitag M, Teuscher J, Saygili Y, Zhang X, Giordano F, Liska P, et al. Dye-sensitized solar cells for efficient power generation under ambient lighting. Nat Photonics. 2017; 11: 372-378.

76) Michaels H, Rinderle M, Freitag R, Benesperi I, Edvinsson T, Socher R, et al. Dye-sensitized solar cells under ambient light powering machine learning: towards autonomous smart sensors for the

77) Freitag M, Giordano F, Yang W, Pazoki M, Hao Y, Zietz B, et al. Copper phenanthroline as a fast and high-performance redox mediator for dye-sensitized solar cells. J Phys Chem C. 2016; 120: 9595603. investigation of interfacial charge dynamics with cobalt and iodine based electrolytes. J Mater Chem A. 2018; 6: 22204-14. 
946 79) Freitag M, Daniel Q, Pazoki M, Sveinbjornsson K, Zhang J, Sun L, et al. High-efficiency dye947 sensitized solar cells with molecular copper phenanthroline as solid hole conductor. Energy Environ 948 Sci. 2015; 8: 2634-2637.

80) Kashif MK, Milhuisen RA, Nippe M, Hellerstedt J, Zee DZ, Duffy NW, et al. Cobalt Polypyridyl Complexes as Transparent Solution-Processable Solid-State Charge Transport Materials. Adv Energy Mater. 2016; 6: 1600874.

953

81) Michaels H, Benesperi I, Edvinsson T, Muñoz-Garcia AB, Pavone M, Boschloo G, et al. Copper Complexes with Tetradentate Ligands for Enhanced Charge Transport in Dye-Sensitized Solar Cells. Inorganics. 2018; 6: 130.

957

82) Zerk TJ, Saouma CT, Mayer JM, Tolman WB. Low Reorganization Energy for Electron Self-

83) Higashino $T$, liyama $H$, Nimura $S$, Kurumisawa $Y$, Imahori $H$. Effect of Ligand Structures of Copper Redox Shuttles on Photovoltaic Performance of Dye-Sensitized Solar Cells. Inorg Chem. 2020; 59: 452-9.

84) Rodrigues RR, Lee JM, Taylor NS, Cheema H, Chen L, Fortenberry RC, et al. Copper-based redox shuttles supported by preorganized tetradentate ligands for dye-sensitized solar cells. Dalt Trans. 2020; 49: 343-55.

85) Glinka A, Gierszewski M, Gierczyk B, Burdziński G, Michaels H, Freitag M, et al. Interface 970 Modification and Exceptionally Fast Regeneration in Copper Mediated Solar Cells Sensitized with 971 Indoline Dyes. J Phys Chem C. 2020; 124: 2895-906.

973 86) Kubota Y, Kimura K, Jin J, Manseki K, Funabiki K, Matsui M. Synthesis of near-infrared absorbing 974 and fluorescing thiophene-fused BODIPY dyes with strong electron-donating groups and their application in dye-sensitised solar cells. New J Chem. 2019; 43: 1156-1165. 
977 87) Haishima $\mathrm{Y}$, Kubota $\mathrm{Y}$, Manseki K, Jin J, Sawada $\mathrm{Y}$, Inuzuka T, et al. Wide-Range Near-Infrared 978 Sensitizing 1H-Benzo[c,d]indol-2-ylidene-Based Squaraine Dyes for Dye-Sensitized Solar Cells. J Org 979 Chem. 2018; 83: 4389-4401.

980

981

88) Barbero N, Magistris C, Park J, Saccone D, Quagliotto P, Buscaino R, et al. Microwave-Assisted 983

89) Wu J, Lan Z, Lin J, Huang M, Huang Y, Fan L, et al. Counter electrodes in dye-sensitized solar 985 cells. Chem. Soc. Rev. 2017; 46: 5975-6023.

986

987

90) Velten J, Mozer AJ, Li D, Officer D, Wallace G, Baughman R, et al. Carbon nanotube/graphene 988 nanocomposite as efficient counter electrodes in dye-sensitized solar cells. Nanotechnology. 2012; 23: 085201.

990

991

91) Yang Z, Liu M, Zhang C, Tjiu WW, Liu T, Peng H. Carbon nanotubes bridged with graphene 992 nanoribbons and their use in high-efficiency dye-sensitized solar cells. Angew Chem Int Ed. 2013; 52: 3996-3999.

994

995

92) Kavan L, Saygili Y, Freitag M, Zakeeruddin SM, Hagfeldt A, Grätzel M. Electrochemical 996 Properties of $\mathrm{Cu}(\mathrm{II} / \mathrm{I})$-Based Redox Mediators for Dye-Sensitized Solar Cells. Electrochim Acta. 2017; 227: 194-202.

998

93) Kay A, Grätzel M. Low cost photovoltaic modules based on dye sensitized nanocrystalline 1000 titanium dioxide and carbon powder. Sol Energy Mater Sol Cells. 1996; 44: 99-117.

1001

1002 94) Stefik M, Yum JH, Hu Y, Grätzel M. Carbon-graphene nanocomposite cathodes for improved 1003 Co(ii/iii) mediated dye-sensitized solar cells. J Mater Chem A. 2013; 1: 4982-4987.

1004

1005 95) Yella A, Lee H-WH-WW, Tsao HNHN, Yi C, Chandiran AKAK, Nazeeruddin MKK, et al. 1006 Porphyrin-sensitized solar cells with cobalt (II/III)-based redox electrolyte exceed 12 percent efficiency. 1007 Science. 2011; 334: 629-634.

1008 
1009

1010

1011

1012

1013

1014

1015

1016

1017

1018

1019

1020

1021

1022

1023

1024

1025

1026

1027

1028

1029

1030

1031

1032

1033

1034

1035

1036

1037

1038

1039

1040

1041

1042

96) Mathew S, Yella A, Gao P, Humphry-Baker R, Curchod BFE, Ashari-Astani N, et al. Dyesensitized solar cells with $13 \%$ efficiency achieved through the molecular engineering of porphyrin sensitizers. Nat Chem. 2014; 6: 242-247.

97) Sauvage F. A Review on Current Status of Stability and Knowledge on Liquid Electrolyte-Based Dye-Sensitized Solar Cells. Adv Chem. 2014; 2014: 1-23.

98) Asghar MI, Miettunen K, Halme J, Vahermaa P, Toivola M, Aitola K, et al. Review of stability for advanced dye solar cells. Energy Environ Sci. 2010; 3: 418-426.

99) Iftikhar H, Sonai GG, Hashmi SG, Nogueira AF, Lund PD. Progress on electrolytes development in dye-sensitized solar cells. Materials. 2019; 12: 1998.

100) Hashmi SGSG, Ozkan M, Halme J, Misic KDKD, Zakeeruddin SMSM, Paltakari J, et al. High performance dye-sensitized solar cells with inkjet printed ionic liquid electrolyte. Nano Energy. 2015; 17: 206-215.

101) Kato N, Higuchi K, Tanaka H, Nakajima J, Sano T, Toyoda T. Improvement in long-term stability of dye-sensitized solar cell for outdoor use. Sol Energy Mater Sol Cells. 2011; 95: 301-305.

102) Hattori S, Wada Y, Yanagida S, Fukuzumi S. Blue copper model complexes with distorted tetragonal geometry acting as effective electron-transfer mediators in dye-sensitized solar cells. J Am Chem Soc. 2005; 127: 9648-9654.

103) Bai $Y$, Yu Q, Cai N, Wang Y, Zhang M, Wang P. High-efficiency organic dye-sensitized mesoscopic solar cells with a copper redox shuttle. Chem Commun. 2011; 47: 4376-4378.

104) Reese MO, Gevorgyan SA, Jørgensen M, Bundgaard E, Kurtz SR, Ginley DS, et al. Consensus stability testing protocols for organic photovoltaic materials and devices. Sol Energy Mater Sol Cells. 2011; 95: 1253-1267.

105) Khenkin M V., Katz EA, Abate A, Bardizza G, Berry JJ, Brabec C, et al. Consensus statement for stability assessment and reporting for perovskite photovoltaics based on ISOS procedures. Nat Energy. 2020; 5: 35-49. 
1044 106) Kavan L, Krysova H, Janda P, Tarabkova H, Saygili $Y$, Freitag M, et al. Novel highly active $1045 \mathrm{Pt} / \mathrm{graphene}$ catalyst for cathodes of $\mathrm{Cu}(\mathrm{II} / \mathrm{I})$-mediated dye-sensitized solar cells. Electrochim Acta. 1046 2017; 251: 167-175.

1047

1048

107) García-Rodríguez R, Jiang R, Canto-Aguilar EJ, Oskam G, Boschloo G. Improving the mass 1049 transport of copper-complex redox mediators in dye-sensitized solar cells by reducing the inter1050 electrode distance. Phys Chem Chem Phys. 2017; 19: 32132-32142.

1051

1052

108) Yella A, Mathew S, Aghazada S, Comte P, Grätzel M, Nazeeruddin MK. Dye-sensitized solar 1053 cells using cobalt electrolytes: the influence of porosity and pore size to achieve high-efficiency. J Mater 1054 Chem C. 2017; 5: 2833-2843.

1055

1056

109) Pettersson H, Gruszecki T, Johansson L-H, Johander P. Manufacturing method for monolithic 1057 dye-sensitised solar cells permitting long-term stable low-power modules. Sol Energy Mater Sol Cells. 1058 2003; 77: 405-413.

1059

1060

110) Pettersson H, Gruszecki T, Bernhard R, Häggman L, Gorlov M, Boschloo G, et al. The monolithic 1061 multicell: a tool for testing material components in dye-sensitized solar cells. Prog Photovoltaics Res 1062 Appl. 2007; 15: 113-121.

1063

1064

111) Hashmi SG, Halme J, Saukkonen T, Rautama E-L, Lund P. High performance low temperature 1065 carbon composite catalysts for flexible dye sensitized solar cells. Phys Chem Chem Phys; 15: 176891066 17695.

1067

1068

1069

112) Yue GT, Wu JH, Xiao YM, Lin JM, Huang ML, Fan LQ, et al. A dye-sensitized solar cell based on PEDOT: PSS counter electrode. Chinese Sci Bull. 2013; 58: 559-566.

1070

1071

1072

1073

113) Kaskela A, Nasibulin AG, Timmermans MY, Aitchison B, Papadimitratos A, Tian $Y$, et al. Aerosolsynthesized SWCNT networks with tunable conductivity and transparency by a dry transfer technique. 
1075

1076

1077

1078

1079

1080

1081

1082

1083

1084

1085

1086

1087

1088

1089

1090

1091

1092

1093

1094

1095

1096

1097

1098

1099

1100

1101

1102

1103

1104

1105

1106

1107

1108
114) Aitola K, Kaskela A, Halme J, Ruiz V, Nasibulin AG, Kauppinen El, et al. Single-Walled Carbon Nanotube Thin-Film Counter Electrodes for Indium Tin Oxide-Free Plastic Dye Solar Cells. J Electrochem Soc. 2010; 157: B1831-B1837.

115) Aitola K, Sveinbjörnsson K, Correa-Baena JP, Kaskela A, Abate A, Tian Y, et al. Carbon nanotube-based hybrid hole-transporting material and selective contact for high efficiency perovskite solar cells. Energy Environ Sci. 2015; 9: 461-466.

116) Wang X, Zhi L, Müllen K. Transparent, conductive graphene electrodes for dye-sensitized solar cells. Nano Lett. 2008; 8: 323-327.

117) Dodoo-Arhin D, Howe RCT, Hu G, Zhang Y, Hiralal P, Bello A, et al. Inkjet-printed graphene electrodes for dye-sensitized solar cells. Carbon N Y. 2016; 105: 33-41.

118) Pang B, Dong L, Ma S, Dong H, Yu L. Performance of FTO-free conductive graphene-based counter electrodes for dye-sensitized solar cells. RSC Adv. 2016; 6: 41287-41293.

119) Chu Z, Wang $Y$, Jiao L, Zhang X. Laser-scribed reduced graphene oxide as counter electrode for dye-sensitized solar cell. Fullerenes Nanotub Carbon Nanostructures. 2019; 27: 914-919.

120) Jia G, Plenz J, Andrä G. Verfahren zur Beschichtung eines Substrats mit Graphen. Patent DE 102017106 807.4, Germany, 2017.

121) Jia G, Plentz J, Presselt M, Dellith J, Dellith A, Patze S, et al. A Double Self-Assembly Process for Versatile Reduced-Graphene-Oxide Layer Deposition and Conformal Coating on 3D Structures. Adv Mater Interfaces. 2017; 4: 1700758.

122) Jia G, Plentz J, Dellith J, Dellith A, Wahyuono RA, Andrä G. Large area graphene deposition on hydrophobic surfaces, flexible textiles, glass fibers and 3D structures. Coatings. 2019; 9: 183.

123) Wahyuono RA, Jia G, Plentz J, Dellith A, Dellith J, Herrmann-Westendorf F, et al. Self-Assembled Graphene/MWCNT Bilayers as Platinum-Free Counter Electrode in Dye-Sensitized Solar Cells. ChemPhysChem. 2019; 20: 3336-45. 
1109 124) Jia G, Gawlik A, Plentz J, Andrä G. Bifacial multicrystalline silicon thin film solar cells. Sol Energy 1110 Mater Sol Cells. 2017; 167: 102-8.

1111

1112

125) Wu J, Li Y, Tang Q, Yue G, Lin J, Huang M, et al. Bifacial dye-sensitized solar cells: A strategy

1113 to enhance overall efficiency based on transparent polyaniline electrode. Sci Rep. 2014; 4: 1-7.

1114

1115

126) Hashemi SA, Ramakrishna S, Aberle AG. Recent progress in flexible-wearable solar cells for 1116 self-powered electronic devices. Energy Environ Sci. 2020; 13: 685-743.

1117

1118

127) Arat R, Jia G, Plenz J. Chemical Treatment of Graphene Films to Improve Electrical Conductivity.

1119 To be published in Curr Appl Phys. 2020.

1120

1121

128) Moon IK, Lee J, Ruoff RS, Lee H. Reduced graphene oxide by chemical graphitization. Nat 1122 Commun. 2010; 1: 1-6.

1123 